\title{
The Impact of COVID-19 Pandemic on the Developing Nations: Emerging Mental Health Challenges and Interventions
}

\author{
Flavia Sharlet Noronha ${ }^{1}$, Sanju Pant ${ }^{2}$, Renjulal Yesodharan ${ }^{3}$, Asha K Nayak ${ }^{4}$, Rochelle Jane Dsa ${ }^{5}$
}

${ }^{1}$ Lecturer, Department of Psychiatric Nursing, Manipal College of Nursing, Manipal Academy of Higher Education, Manipal, Karnataka, India; ${ }^{2}$ Lecturer, Department of Psychiatric Nursing, Manipal College of Nursing, Manipal Academy of Higher Education, Manipal, Karnataka, India; ${ }^{3}$ Assistant Professor, Department of Psychiatric Nursing, Manipal College of Nursing, Manipal Academy of Higher Education, Manipal, Karnataka; ${ }^{4}$ Assistant Professor, Department of Psychiatric Nursing, Manipal College of Nursing, Manipal Academy of Higher Education, Manipal, Karnataka; ${ }^{5}$ Registered Nurse, Carleton Clinic, Carlisle, United Kingdom.

\begin{tabular}{|c|c|c|c|c|c|c|c|c|}
\hline Abstract & Introduction & Methodology & Results & Conclusion & References & Citation & \multicolumn{2}{|c|}{ Tables / Figures } \\
\hline \multicolumn{9}{|c|}{ Corresponding Author } \\
\hline \multicolumn{8}{|c|}{$\begin{array}{l}\text { Renjulal Yesodharan, Assistant Professor, Department of Psychiatric Nursing, Manipal College of Nursing, } \\
\text { Manipal Academy of Higher Education, Manipal, Karnataka } 576104 \\
\text { E Mail ID: renjulal.y@manipal.edu }\end{array}$} & 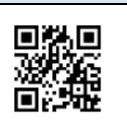 \\
\hline
\end{tabular}

\section{Citation}

Noronha FS, Pant S, Yesodharan R, Nayak AK, Dsa RJ. The Impact of COVID-19 Pandemic on the Developing Nations: Emerging Mental Health Challenges and Interventions. Indian J Comm Health. 2021;33(3):419-423. https://doi.org/10.47203/IJCH.2021.v33i03.002

Source of Funding: Nil Conflict of Interest: None declared

\section{Article Cycle}

\begin{tabular}{|c|}
\hline Received: 21/05/2021; Revision: 24/06/2021; Accepted: 20/07/2021; Published: 30/09/2021 \\
\hline This work is licensed under a Creative Commons Attribution 4.0 International License. \\
\hline
\end{tabular}

\section{Abstract}

The world is facing an unprecedented challenge of the 21st century in the form of COVID-19 outbreak. People across the culture, race, ethnicity, socio-economic background are being affected by the rippling effects of this pandemic. The aim of this narrative review is to briefly describe the impact of the pandemic on mental health, the vicious cycle of social issues and psychological health caused and aggravated by the Covid-19 pandemic. We also aim to highlight certain interventions to overcome the mental health challenges posed by the pandemic. For this purpose, a thorough search of all databases was done to gather articles relevant to the objective of this narrative review. Keywords were used in combination and separately to identify the articles on the various psychosocial issues caused by the pandemic. Published articles in various databases like Scopus, Web of Science, Pubmed etc., related to psychosocial effects due to COVID-19 were searched and summarized to justify and support the objective of this paper. The coming months will reveal the extent of damage this pandemic has caused to the socio-economic and health sectors across the globe. It is crucial to recognize the psychosocial impact of this pandemic and necessitate the measures to overcome them by mobilizing the resources we have at hand.

\section{Keywords}

Covid19; Mental Health; Pandemic; Suicide; Violence

\section{Introduction}

The Coronavirus disease 2019 (COVID-19) was unknown until the outbreak began in Wuhan, China, in December 2019 (1), but in the present scenario, experts across the world agree unanimously that the post-covid world will be a challenging place to survive. There will be a huge rise in mental health issues emerging from unemployment, poverty, social distancing and unprecedented violence at the doorstep $(2,3)$. The crisis stage has seen a surge in mental health issues across the world like domestic violence, gaming addiction, job losses, aggression due to alcohol withdrawal symptoms during lockdown, stress and anxiety issues related to fear of the disease and aggressive behavior towards health care personnel.

\section{Aim \& Objective}

The aim of this narrative review is to briefly describe the impact of the pandemic on mental health, the vicious cycle of social issues and psychological health caused and aggravated by the Covid-19 pandemic, with an objective highlighting certain interventions to overcome mental health challenges posed by the pandemic.

\section{Material \& Methods}

A thorough search of all databases was done to gather articles relevant to the objective of this narrative review. 
Keywords were used in combination and separately to identify the articles on the various psychosocial issues caused by the pandemic. The data obtained from various published articles are summarized below to justify and support the objective of this paper.

\section{Results}

Suicides: Though there is no scientific association proved between suicides and pandemics, COVID19 has certainly seen a rise in suicidal behavior or the number of suicides globally. People from low socio-economic status, people with pre-existing mental illness or with a history of substance abuse, are at greater risk. Developing nations, in particular, provide minimal assistance to their population in times of crisis, leaving them vulnerable to fend for themselves. It was found that there was an increase of $7.2 \%$ in the average annual factor of first-time hospitalized patients with mental disorders in the six years following Spanish influenza and the influenza death rates were significantly and positively related to suicide (4). Studies in India reported around 140 suicides (5) for various reasons like alcohol withdrawal, fear of being infected with coronavirus, stigma, loss of job, lack of food for the family members etc., during the lockdown period itself in India (6). The following data from recent studies on Covid related suicide is summarized as [Table 1]

Psychological issues of Health Care Professionals (HCP): The frontline workers bear the brunt in every pandemic/epidemic or disaster. The unpredictable situation and the uncertainty caused by the pandemic/epidemic does have a negative impact on the mental health of HCP. Twenty-three percent of the HCP engaged in direct COVID-19 patient care had psychosocial problems. Among these nurses (81.13\%) were the most affected. The most common mental health problems were found to be anxiety, stress disorder, depression, and insomnia at $44 \%, 71 \%, 50.4 \%$ and $34 \%$, respectively $(7,8,9,10)$. As the long-term effect, it was found that about $10 \%$ of the HCP experienced high levels of post-traumatic stress symptoms even after three years of the SARS outbreak in 2003 (11). These psychological effects of the pandemic will further reduce the resilience power of our HCP.

Job losses, economic turmoil and poverty: Developing countries have been facing the problem of unemployment despite several policy emphasis and programmes. The vicious cycle of unemployment, poverty and impoverished mental health is best explained through the fact that poverty increases the vulnerability to common mental disorders, and the presence of mental disorders increases the likelihood of facing unemployment and poverty. COVID19 pandemic has its own rippling effect and among the plethora of health risks, this pandemic has also pushed us into global economic turmoil. The unemployment rate rose to $23 \%$ in India (12). Fifty-four per cent of the unemployed people reported negative mental health impacts like stress and worry with regard to the Covid19 infection (13). In two different studies, it was seen that unemployed people were at greater risk for mental health issues like anxiety (19.8\% and 35.89$)$, depression (42.2\% and 17.64) and psychological distress (14,15). A United Nations University World Institute for Development Economics Research (UNU-WIDER) study estimated that half a billion people could be pushed into poverty in developing countries due to this pandemic (16). A systematic review of community-based studies has shown that $79 \%$ of the studies depict positive associations between poverty and common mental disorders. [Figure 1] $(17,18)$

Witnessing or learning of violence to a loved one: There has been an exponential increase in domestic violence around the world. Witnessing violence as a victim or as a bystander has adverse effects on mental health. The data shared by National Commission for Women, India revealed that a total of 370 complaints were received, out of which the highest 123 were related to domestic violence during the first week of lockdown in 2020 (19). All these complaints were received through the mail, which indicates that the number could have been much higher if the other means of sending complaints were accessible for the victims. Economic instability, cultural beliefs, patriarchal society are some of the factors aggravating the situation of domestic violence in India. The COVID19 crisis and the very measures implemented for its control, like stay-at-home and social distancing, have led to the rise in domestic violence and restricted access to essential services like counselling and psychological support. Domestic violence or intimate partner violence has gradually grown into "a pandemic within a pandemic", as some social researchers have rightly mentioned.

Social distancing and social behavior: Social distancing is one of the best practices to fight an infectious droplet disease, but it has its own adverse effects on the mental well-being of the vulnerable and an unprepared population. It has been shown that there are long term effects of prolonged social distancing, and it can vary from irritability, anger, confusion, loneliness, anxiety, avoidance behavior, depression, and despair to suicide (20). The previous pandemics had a long-lasting influence on human behavior, such as a decline in social trust, which mainly resulted from the social disruption caused by the pandemics (21). Themes such as "loss of motivation and self-worth" and "lingering concerns about social contact" are being reported by the general public (22). We are witnessing something similar at this point in time; the fear of contracting the disease will have a consequential effect on our social behavior and interactions in the future, leading to a further rise in loneliness and mental illness.

Changed work demands and responsibility stressors: We are facing the new normal, where daily routines are disrupted, and other factors like isolation from colleagues and friends, homeschooling children and household 
chores has only added to the stressors. An article (23) by Opinium (a market research organization) found that $46 \%$ of the participants felt isolated, whereas $51 \%$ felt more relaxed while working from home. The problem was in situations where a person was living alone, where $47 \%$ reported struggles with their mental health. Working parents juggling with homeschooling for their children and house responsibilities, $41 \%$ reported an increase in their stress levels. Around $57 \%$ find it difficult to work from home with their children around. [Figure 2]

Mental Health Interventions for the post COVID world: Pandemics are not isolated events; they have rippling effects on the individual and society. These times with its psychosocial effects are going to stay with us for a long time to come, and we will have to suffice this surge in demand for mental health care in our society, amongst our loved ones and for ourselves. Here we are discussing a few interventions which need to be strengthened for a developing country to overcome the psychosocial effects of a pandemic. [Figure 3]

Identify the vulnerable population: The ability and mechanism to identify the vulnerable population will provide a strong head start in mitigating the psychological issues post-disaster. Providing support and promoting mental health will help in changing the course from treatment to prevention and promotion. For this reason, we have attempted to identify and triage the vulnerable population of this pandemic as classified below based on the psychological effects:

- Primary clients: People infected with novel coronavirus infection / People with already existing mental illness / Frontline workers

- Secondary clients: Family members, relatives, and friends of the primary clients

- Third-level clients: All those indirectly affected by the pandemic

Immediate response: It is better to integrate crisis intervention measures into the overall covid-19 mitigation plan. Psychological first aid (PFA) is one such immediate response that is designed to mitigate acute distress and assess the need for continued mental health care. It can be provided by mental health experts or others trained in PFA. The National Child Traumatic Stress Network, which developed the concept of PFA, elaborates on the steps to alleviate the immediate suffering from a post-traumatic event and provide stability to the affected individual. Recovery from post-traumatic stress symptoms (PTSS) can be modulated through the basic human responses of comforting, protecting, and linking the distressed person to systems of support that will be ongoing and identifying needs for follow-up counselling or interventions.

Gatekeepers in the society: Building acute intervention resources by training those people who regularly interface with the public can contribute substantially to suffice the demand for mental health services. A post interventional study among the aboriginal population of Australia revealed that 15 of the 40 participants had helped someone at risk of suicide over the 2-year follow-up period of gatekeeper training (24). The Systematic Medical Appraisal, Referral and Treatment (SMART) mental health project carried out in 30 remote villages of Andhra Pradesh evaluated the task shifting approach in the community from the psychiatrist to accredited social health activist (ASHA) through mobile technology-based electronic decision support systems. This intervention was found to be effective in increasing the utilization of mental health services from (0.8\% to $12.6 \%)(25)$. India already has a decentralized public healthcare delivery system which could be further strengthened by having more gatekeepers at the grassroots levels.

Support for healthcare professionals: Providing virtual support for the frontline workers is called upon across the world. Effective and frequent communication from the hospital authority, transparency, and flexibility among the leadership in dealing with the workers, and robust plans for the welfare of the staff will boost the morale of the healthcare professionals (26). Tele-mental health, video conferencing platforms, virtual townhalls are some of the methods where experienced professionals can help the frontline workers to overcome stress, not only for the present scenario but also for the future. Technology in the form of mobile-based applications to artificial intelligence should be made used to reduce the burden on the overstretched health care system (27). Also, these advanced technologies, if put into right use, will help to overcome the disparities in access to mental health care in India. Developing nations should also work on strengthening the linkages between HCP safety, patient safety, infection control and quality control programs. Increased incidences of violence against HCP can be dealt with a zero-tolerance policy, followed by stringent laws against the perpetrators.

Programs for the geriatric population: The elderly are at a higher risk of infection, and physical distancing seems to be safe, but this should not lead to social isolation. Increased effort should be made to help them in meeting their physical, social, and psychological needs. It was found that $86 \%$ of the elderly were satisfied with telepsychiatry services, and $76 \%$ would like to use them again. Among the psychiatrist, $92.7 \%$ would encourage the use of telepsychiatry services, whereas $55 \%$ preferred it to face-to-face consultation (28). These findings should serve as a strong indicator for building community-based telepsychiatry services for the elderly population. One of the advantages of providing telepsychiatry services is that it will surely help to bridge the treatment gap.

School-based mental health programs: Mean scores of self-efficacies in regulating negative emotions baseline (23.0), postintervention (23.9)\}, overall psychological well-being \{baseline (355.7), postintervention (361.4)\} and life satisfaction baseline (24.2), postintervention (25.4)\} improved in the intervention group, after the 
implementation of school-based mental health program in Italy (29). It also established that among the other psychological dimensions, the school-based mental health program significantly improved the mean scores in environmental mastery \{baseline (57.6), postintervention (59.0)\} and self-acceptance \{baseline (56.9), postintervention (59.4)\}. A study on the impact of life skills school-based mental health program in Bangalore, India, found that the program had significantly increased perceived self-efficacy, self-esteem, and general adjustment in the intervention group (31.84 \pm 5.08 , $28.66 \pm 3.6,31.02 \pm 3.92)$ when compared to the control group $(29.19 \pm 5.11,27.28 \pm 3.6,29.83 \pm 4.79)$ on the same parameters (30). Despite the scientific evidence, most of the schools have reported that they do not or have inadequate services to promote mental health for their children $(31,32)$. If we need to decentralize the mental health services, then school-based mental health programs need to be strengthened and invested upon.

\section{Conclusion}

The COVID pandemic has brought the world to a standstill, and the coming months will just reveal the extent of damage it has caused. It is crucial to recognize the psychosocial impact of this pandemic and necessitate the measures to overcome them by mobilizing the resources we have at hand.

\section{Authors Contribution}

All authors have contributed equally.

\section{References}

1. Wang X, Zhou Q, He Y, Liu L, Ma X, Wei X, et al. Nosocomial outbreak of COVID-19 pneumonia in Wuhan, China. Eur Respir J [Internet] 2020;55(6). Available from: https://doi.org/10.1183/13993003.005442020. (Accessed on 25/09/2021)

2. Wan William. Coronavirus is causing a historic rise in mental health problems, experts warn - The Washington Post. Washington Post. 2020 Available from: https://www.washingtonpost.com/health/2020/05/04/mental-healthcoronavirus/. Accessed on 25/09/2021

3. WHO/Europe. Mental health and COVID-19 [Internet]. World Health Organization. World Health Organization; 2020. Available from: https://www.euro.who.int/en/health-topics/healthemergencies/coronavirus-covid-19/technical-guidance/mental-healthand-covid-19. (Accessed on 25/09/2021)

4. Greg E. The Spanish Flu Pandemic and Mental Health: A Historical Perspective | Psychiatric Times [Internet]. Psychiatric Times. 2020. Available

from: https://www.psychiatrictimes.com/coronavirus/spanish-flu-pandemicand-mental-health-historical-perspective. (Accessed on 25/09/2021)

5. Pathare S. Suicide Cases during Corona Lockdown in India: Is There a Rise in Suicides in the COVID-19 Lockdown? An Expert Answers, Suicide Myths Debunked [Internet]. Quint. 2020. Available from: https://fit.thequint.com/mind-it/rise-in-suicides-in-the-coronaviruscovid-19-lockdown-expert-answers. (Accessed on 25/09/2021)

6. Rajkumar RP. Suicides related to the COVID-19 outbreak in India: A pilot study of media reports. Asian J Psychiatr. 2020;53:102196. Available from: https://www.ncbi.nlm.nih.gov/pmc/articles/PMC7274089/. (Accessed on 25/09/2021)

7. Pathare S, Vijayakumar L, Fernandes TN, Shastri M, Kapoor A, Pandit D, et al. Analysis of news media reports of suicides and attempted suicides during the COVID-19 lockdown in India. Int J Ment Health Syst 2020;14(1):88. Available from: https://ijmhs.biomedcentral.com/articles/10.1186/s13033-02000422-2. (Accessed on 25/09/2021)
[Emerging Mental Health...] | Noronha FS et al

8. Panigrahi M, Pattnaik JI, Padhy SK, Menon V, Patra S, Rina K, et al. COVID-19 and suicides in India: A pilot study of reports in the media and scientific literature. Asian J Psychiatr. 2021;57:102560. Available from: /pmc/articles/PMC7804380/ (Accessed on 25/09/2021)

9. Mamun MA, Akter T, Zohra F, Sakib N, Bhuiyan AKMI, Banik PC, et al. Prevalence and risk factors of COVID-19 suicidal behavior in Bangladeshi population: are healthcare professionals at greater risk? Heliyon. 2020;6(10):e05259.

10. Lai J, Ma S, Wang Y, Cai Z, Hu J, Wei N, et al. Factors Associated With Mental Health Outcomes Among Health Care Workers Exposed to Coronavirus Disease 2019. JAMA Netw open. 2020;3(3):e203976. Available from: https://jamanetwork.com/. (Accessed on 25/09/2021)

11. Wu P, Fang Y, Guan Z, Fan B, Kong J, Yao Z, et al. The psychological impact of the SARS epidemic on hospital employees in China: Exposure, risk perception, and altruistic acceptance of risk. Can J Psychiatry [Internet]. 2009;54(5):302-11. Available from: https://pubmed.ncbi. nlm.nih.gov/19497162/. (Accessed on 25/09/2021)

12. Mahesh V. Unemployment range shoots out of range [Internet]. Mumbai; $2020 . \quad$ Available from: https://www.cmie.com/kommon/bin/sr.php?kall=warticle\&dt=202004-07 08:26:04\&msec=770. (Accessed on 25/09/2021)

13. Panchal N, Kamal R, Orgera K, Cox C, Garfield R, Hamel L, et al. The Implications of COVID-19 for Mental Health and Substance Use | KFF [Internet]. Kaiser Family Foundation. 2020. Available from: https://www.kff.org/coronavirus-covid-19/issue-brief/theimplications-of-covid-19-for-mental-health-and-substance-use/. (Accessed on 25/09/2021)

14. Bhat MA, Joshi J. Impact of Unemployment on the Mental Health of Youth in the Kashmir Valley. J Psychol Psychother. 2020;10(372).

15. Navarro-Abal Y, Climent-Rodríguez JA, López-López MJ, Gómez-Salgado J. Psychological coping with job loss. Empirical study to contribute to the development of unemployed people. Int J Environ Res Public Health. 2018;15(8). Available from: /pmc/articles/PMC6122016/?report=abstract. (Accessed on 25/09/2021)

16. Summer A, Ortiz-Juarez E, Hoy C. Precarity and the pandemic: Covid-19 and poverty incidence, intensity and severity in developing countries, UN-WIDER working paper 2020/77. 2020. Available from: https://www.wider.unu.edu/publication/precarity-and-pandemic. (Accessed on 25/09/2021)

17. Lund C, Breen A, Flisher AJ, Kakuma R, Corrigall J, Joska JA, et al. Poverty and common mental disorders in low and middle income countries: $A$ systematic review. Soc Sci Med. 2010;71(3):517-28. Available from: https://pubmed.ncbi.nlm.nih.gov/20621748/. (Accessed on 25/09/2021)

18. Sapkal RS, Shandilya D, Majumdar K, Chakraborty R, Suresh KT. Workers in the time of Covid-19. 2020. Available from: www.actionaidindia.org@company/actionaidindia. (Accessed on 25/09/2021)

19. Jagriti C. NCW records sharp spike in domestic violence amid lockdown. The Hindu. 2020.2 Available from: https://www.thehindu.com/news/national/ncw-records-sharp-spikein-domestic-violence-amid-lockdown/article31835105.ece. (Accessed on 25/09/2021)

20. Brooks SK, Webster RK, Smith LE, Woodland L, Wessely S, Greenberg N, et al. The psychological impact of quarantine and how to reduce it: rapid review of the evidence. Lancet. 2020;395(10227):912-20.

21. Aassve A, Alfani G, Gandolfi F, Le Moglie M. Epidemics and Trust: The Case of the Spanish Flu Epidemics and Trust: The Case of the Spanish Flu \$. Innocenzo Gasparini Institute for Economic Research; 2020. Available from: http://www.igier.unibocconi.it. (Accessed on 25/09/2021)

22. Williams SN, Armitage CJ, Tampe T, Dienes K. Public perceptions and experiences of social distancing and social isolation during the COVID19 pandemic: A UK-based focus group study. medRxiv 2020.04.10.20061267; doi: doi.org/10.1101/2020.04.10.20061267 .

23. The surge in working from home: The effects on mental well-being. UK; 2020. Available from: https://www.opinium.com/wpcontent/uploads/2020/04/The-surge-in-working-from-home-Theeffects-on-mental-wellbeing-1.pdf. (Accessed on 25/09/2021)

24. Deane FP, Capp K, Jones C, de Ramirez D, Lambert G, Marlow B, et al. Two-Year Follow-Up of a Community Gatekeeper Suicide Prevention Program in an Aboriginal Community. Aust J Rehabil Couns [Internet]. 2006;12(1):33-6. Available from: https://www.cambridge.org/core/product/identifier/S1323892200020 
INDIAN JOURNAL OF COMMUNITY HEALTH / VOL 33 / ISSUE NO 03 / JUL-SEP 2021 044/type/journal_article. (Accessed on 25/09/2021)

25. Maulik PK, Kallakuri S, Devarapalli S, Vadlamani VK, Jha V, Patel A. Increasing use of mental health services in remote areas using mobile technology: a pre-post evaluation of the SMART Mental Health project in rural India. J Glob Health. 2017;7(1):010408. Available from: http://www.ncbi.nlm.nih.gov/pubmed/28400954. (Accessed on 25/09/2021)

26. Wu PE, Styra R, Gold WL. Mitigating the psychological effects of COVID19 on health care workers [Internet]. Vol. 192, CMAJ. Canadian Medical Association; 2020 :E459-60. Available from: https://www.ncbi.nlm.nih.gov/pmc/articles/PMC7207194/. (Accessed on $25 / 09 / 2021$ )

27. Krystal JH, McNeil RL. Responding to the hidden pandemic for healthcare workers: stress. Nat Med [Internet]. 2020;26(5):639. Available from: https://doi.org/10.1038/s41591-020-0878-4. (Accessed on 25/09/2021)

28. Dham P, Gupta N, Alexander J, Black W, Rajii T, Skinner E. Community based telepsychiatry service for older adults residing in a rural and remote region- utilization pattern and satisfaction among stakeholders. BMC Psychiatry. 2018;18(1):316. Available from:
[Emerging Mental Health...] | Noronha FS et al https://bmcpsychiatry.biomedcentral.com/articles/10.1186/s12888018-1896-3. (Accessed on 25/09/2021)

29. Gigantesco A, Del Re D, Cascavilla I, Palumbo G, De Mei B, Cattaneo C et al. A universal mental health promotion programme for young people in Italy. Biomed Res Int. 2015;2015.

30. Srikala B, Kishore Kumar K V. Empowering adolescents with life skills education in schools-School mental health program: Does it work. Indian J Psychiatry. 2010;52(4):344-9.

31. Patalay P, Giese L, Stanković M, Curtin C, Moltrecht B, Gondek D. Mental health provision in schools: priority, facilitators and barriers in 10 European countries. Child Adolesc Ment Health. 2016;21(3):139-47. Available from: http://doi.wiley.com/10.1111/camh.12160. (Accessed on 25/09/2021).

32. Parikh R, Michelson D, Sapru M, Sahu R, Singh A, Cuijpers P, et al. Priorities and preferences for school-based mental health services in India: a multi-stakeholder study with adolescents, parents, school staff, and mental health providers. Glob Ment Heal. 2019;6:1-12. Available from: /pmc/articles/PMC6737585/?report=abstract. (Accessed on 25/09/2021)

\section{Tables}

TABLE 1 DEMOGRAPHIC CHARACTERISTICS OF SUICIDAL BEHAVIOR AND COVID RELATED SUICIDE CASES.

\begin{tabular}{|c|c|c|c|c|}
\hline SI no & Study with authors & Characteristics & Number & Percentage \\
\hline \multirow[t]{4}{*}{1} & \multirow{4}{*}{$\begin{array}{l}\text { Analysis of news media reports of suicides and attempted } \\
\text { suicides during the COVID-19 lockdown in India (7) }\end{array}$} & Gender: Male & $232(n=326)$ & 71.2 \\
\hline & & Age: Less than 30 & $146(n=298)$ & 49 \\
\hline & & Occupation: Employed & $160(n=193)$ & 82.9 \\
\hline & & Marital status: Married & $122(n=157)$ & 77.7 \\
\hline \multirow[t]{4}{*}{2} & \multirow{4}{*}{$\begin{array}{l}\text { COVID-19 and suicides in India: A pilot study of reports in } \\
\text { the media and scientific literature ( } 8 \text { ) }\end{array}$} & Gender: Male & $122(n=151)$ & 80.8 \\
\hline & & Age: $25-60$ yrs & $119(n=150)$ & 78.8 \\
\hline & & Marital status: Married & $58(n=151)$ & 38.4 \\
\hline & & Psychiatry illness: Absent & $138(n=151)$ & 91.3 \\
\hline \multirow[t]{4}{*}{3} & \multirow{4}{*}{$\begin{array}{l}\text { Prevalence and risk factors of covid-19 suicidal behavior in } \\
\text { Bangladeshi population: are healthcare professionals at } \\
\text { greater risk? (9) } \\
\text { COVID-19 and suicides in India: A pilot study of reports in } \\
\text { the media and scientific literature (8) }\end{array}$} & Gender: Female & $110(n=1287)$ & 8.5 \\
\hline & & Marital Status: Unmarried & $84(n=1028)$ & 8.2 \\
\hline & & Not having children & $115(n=1510)$ & 7.6 \\
\hline & & Fear of death due to Covid & $78(n=1433)$ & 5.4 \\
\hline
\end{tabular}

Figures

FIGURE 1 BAR DIAGRAM REPRESENTING THE STATUS OF EMPLOYMENT AMONG INFORMAL WORKERS IN INDIA. ( $N=11,159)$

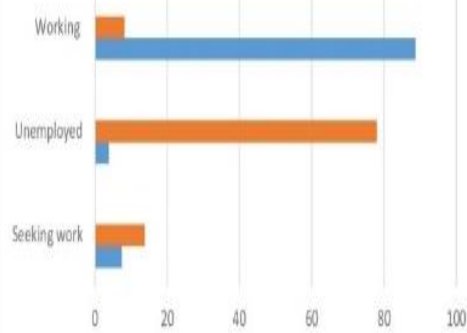

$\begin{array}{lrr}\text { FIGURE } & 2 & \text { DIAGRAM } \\ \text { DEPICTING } & \text { THE }\end{array}$

PSYCHOSOCIAL CHALLENGES POSED BY THE PANDEMIC.

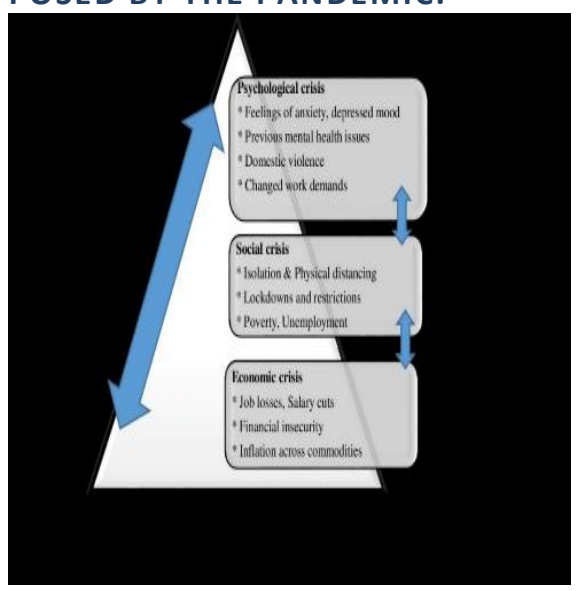

FIGURE 3 PYRAMID OF COMMUNITY-BASED SERVICES TO BE PROVIDED TO REDUCE THE IMPACT CAUSED BY THE COVID-19 PANDEMIC.

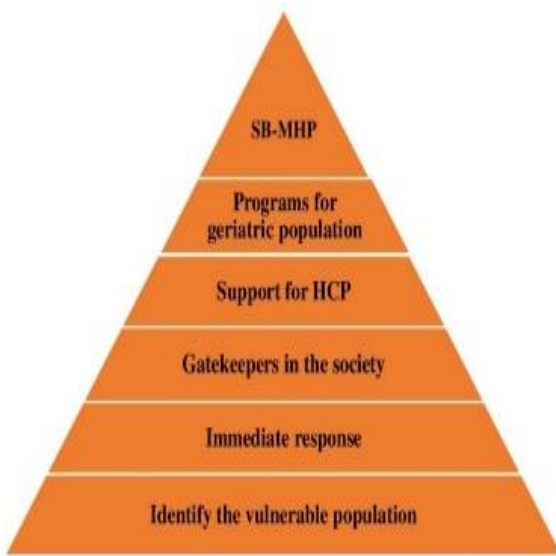

